\title{
Design and implementation of a wind solar hybrid power generation system
}

\author{
DU Yuankun ${ }^{1}$, WANG $\mathrm{Lei}^{2}$, and Wang $\mathrm{Fei}^{3 *}$ \\ ${ }^{1}$ College of Information Engineering,Zhengzhou University of Science and Technology, Zhengzhou, 450064, China \\ ${ }^{2}$ Foundation Department, Zhengzhou University of Science and Technology, Zhengzhou, 450064, China \\ ${ }^{3}$ Henan light Industry vocational College, Zhengzhou, 450064, China
}

\begin{abstract}
Unmanned aerial vehicles (UAV) are becoming more and more popular. In all sectors of society can see the presence of unmanned aerial vehicles. However, the short flight time and flight distance always restrict the development of UAV. The most imminent and creative work is how to make the perfect combination of new energy technologies with UAVs. In this paper, a wind-solar hybrid power generation system and its operation scheme design are discussed, and the application of the wind solar hybrid power generation system controlled by a single-chip microcomputer is discussed. The experimental results show that this kind of power generation system and its operation scheme are improved compared with the conventional design.
\end{abstract}

\section{Introduction}

The traditional power source of UAV is that the UAV carries its batteries. Before the batteries are consumed, the UAV must terminate its flight mission to ensure the UAV take-off and landing within the scope of monitoring, which restricts the UAV's endurance time and efficient flight. Too many batteries will increase the weight of the aircraft, resulting in lower flight efficiency of UAV. Therefore, the design of a simple structure, smooth operation, high efficiency of work and operation, energy saving and environmental protection, fast and straightforward method of UAV, used to overcome many shortcomings in the existing technology, has a broad market prospect.

\section{Overall scheme design}

The utility model relates to a UAV with a wind-solar complementary power generation system, which comprises a battery pack installed on the UAV. The battery pack is connected with a power adapter through wires, and the power adapter is connected with solar panels and wind power generation devices through wires respectively ${ }^{[1]}$.

The solar panels used are photovoltaic or photothermal conversion to generate electricity. Each solar panels uses $12 \mathrm{~V}$ solar panels. The wind power generation device used is driven by windmill blades to generate electricity. Each wind power generation device adopts a $12 \mathrm{~V}$ wind power generation device. The batteries used made of $3 \mathrm{~S}$ smart lithium batteries. Solar panels are installed in the upper lighting position of the $\mathrm{UAV}$, and wind power generation devices are installed in the upper part of the UAV frame or the lower part of the power wing ${ }^{[2]}$.

The overall operation method is as follows: installing solar panels on the upper part of the UAV frame or the casing or the power wing or the horizontal tail wing. Installing wind power generation devices on the upper part of the UAV frame or the lower part of the power wing, and feeding back the energy generated by the solar panels and wind power generation devices to the storage battery through the power adapter to increase the endurance of the UAV, as shown below. It is shown in figure 1 .

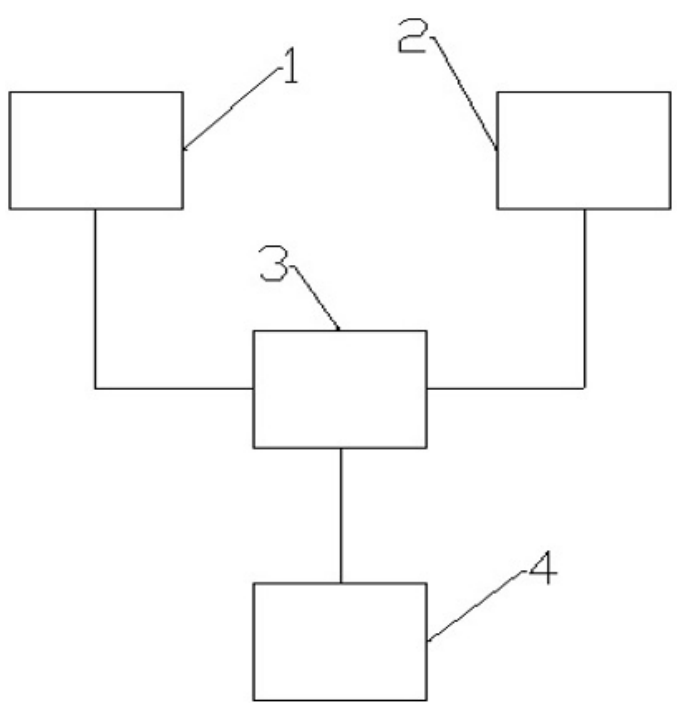

Fig. 1.Overall structure sketch

\footnotetext{
* Corresponding author: 364850991@qq.com
} 


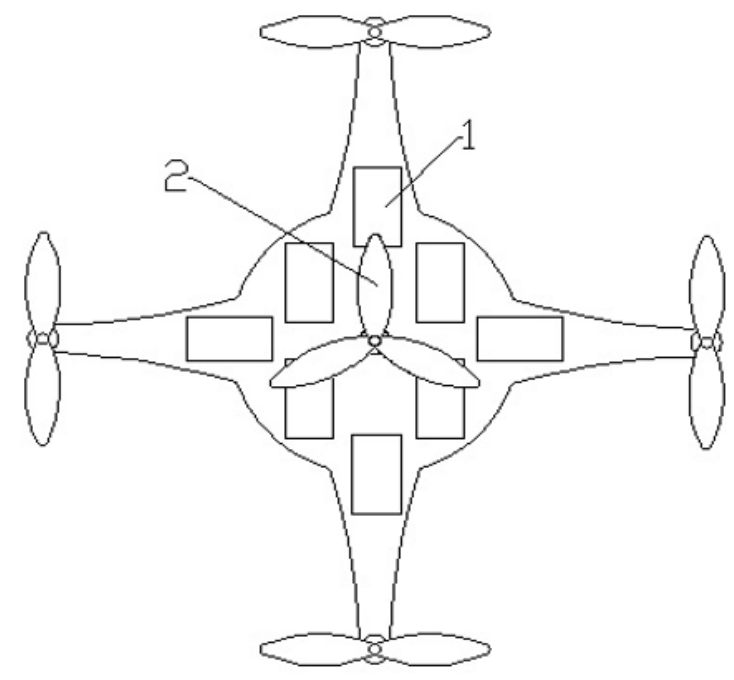

Fig .2.Structural schematic diagram of Four-rotor operating state

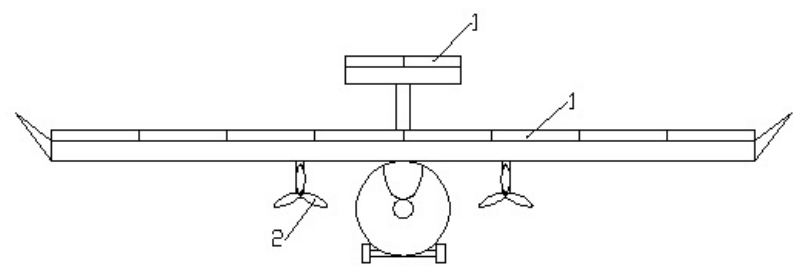

Fig .3. Structural diagram of glider operation status

Specific embodiments: as shown in figs. 1, 2 and 3, an unmanned aerial vehicle wind-solar complementary power generation system includes a storage battery 4 mounted on the unmanned aerial vehicle. The storage battery 4 is connected with the power adapter 3 through wires, and the power adapter 3 is connected with the solar battery 1 and the wind power generation device 2 through wires, respectively. The solar cell board 1 is photoelectric or photoelectric conversion to realize power generation. The solar cell board 1 is at least one, and each solar cell board 1 adopts a $12 \mathrm{~V}$ solar cell board. The wind power generation device 2 is driven by windmill blades to generate electricity. The wind power generation device 2 is at least one, and each wind power generation device 2 adopts a wind power generation device with a specification of $12 \mathrm{~V}$. The battery group 4 is made of $3 \mathrm{~S}$ smart lithium battery. The solar cell board 1 is mounted in the lighting position of the UAV upward. The wind power generation device 2 is installed on the upper part of the UAV frame or the lower part of the power wing ${ }^{[3]}$.

The operation method of the UAV wind-solar complementary power generation system described above is as follows: installing solar cell board 1 on the upper part of the UAV frame or the chassis or the power wing or the horizontal tail wing, installing wind power generation device 2 on the upper part of the UAV frame or the lower part of the power wing, and sending out the solar cell board 1 and the wind power generation device 2 through the power adapter 3 . The power is fed back to the battery pack 4 to increase the endurance of UAV.

Fig. 2 is a four-axis UAV. As shown in the figure 2, the overall frame of the four-axis UAV is unchanged, the solar cell board 1 is added to the upper lighting position of the frame and the casing, and the wind power generator 2 is added to the corresponding part of the propeller (generally the propeller is above, the generator can be installed below) or the central part of the frame. At the same time, the electricity generated by the three pairs of power adapters is added - feedback to the battery pack 4 to increase UAV's endurance. Solar panels are $12 \mathrm{~V}$. If the single solar panels are not enough, series or parallel connection can be used. Wind turbines are $12 \mathrm{~V}$. Unmanned aerial vehicle batteries are $3 \mathrm{~S}$ smart lithium batteries. $12 \mathrm{~V}$ can be charged by power adapter.

Fig. 3 is a gliding UAV. Based on the glider, the upper part of the main wing and horizontal tail of the glider is installed with solar cell board 1, and the bottom part of the main wing of the glider is added with wind power generator 2. At the same time, the power generated by the power adapter 3 is fed back to the battery 4 to increase the endurance of the UAV. Solar panels are $12 \mathrm{~V}$. If the single solar panels are not enough, series or parallel connection can be used. Wind turbines are $12 \mathrm{~V}$. Unmanned aerial vehicle batteries are $3 \mathrm{~S}$ smart lithium batteries. $12 \mathrm{~V}$ can be charged by power adapter.

The UAV rack largely determines whether the unmanned aerial vehicle is good or not. In this design, without changing the rack, the wind-solar complementary system is added to the different positions of the rack to achieve the most complete and reasonable flight and realize the power supply. This design cooperates with UAV's flight control system, power system, electric control system, propeller, camera platform, aircraft platform system, information acquisition system, and ground control system. On the premise of increasing self-weight excessively, wind-solar complementary system provides power supply for UAV and realizes the coordination of components to ensure UAV's stable operation.

\section{$312 \mathrm{~V}$ power adapter design}

Because there are special chargers in the power supply of UAV, such as input DC $15 \mathrm{~V} / 800 \mathrm{~mA}$ and output DC $11.1 \mathrm{~V} / 800 \mathrm{~mA}$, it is only necessary to add a $12 \mathrm{~V}$ power adapter to the wind-solar complementary power generation. A simple adapter is chosen to reduce the weight as much as possible. The schematic diagram is as follows: Main Circuit Design

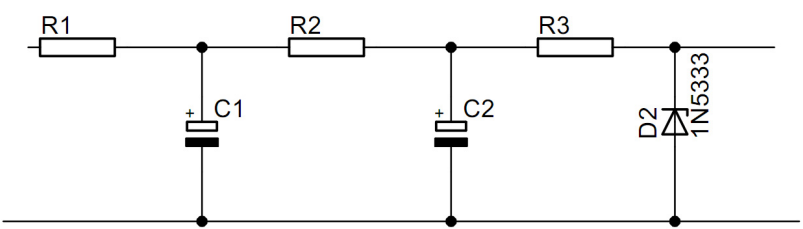


Fig. 4.Principle diagram of main circuit Control Circuit Design

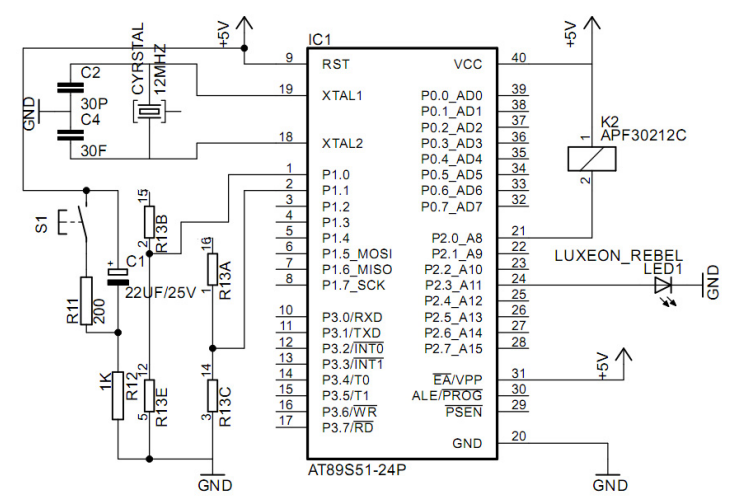

Fig .5. Control circuit schematic diagram

The power generation voltage measured by voltage comparator is above $12 \mathrm{~V}$, and then the high level is acquired by sampling circuit at the PI 1.0 pin of MCU. It shows that the power generation voltage meets the charging requirement and can be charged. The low level is output by the PI 22.0 pin of MCU. The relay control coil of the charging control circuit is energized, and the main circuit is connected. At the same time, the light emitting diode driven by $\mathrm{P} 2.3$ is lit up to indicate charging electricity. The road is charging.

The generating voltage measured by the voltage comparator is below $12 \mathrm{~V}$, and then the low level is collected by the sampling circuit at the PI 1.0 pin of the single-chip computer. It shows that the generating voltage does not meet the charging requirements and cannot be charged. The high level is output by the PI 22.0 pin of the single-chip computer. The relay control coil of the charging control circuit loses power, and the main circuit is disconnected. At the same time, the light emitting diode driven by the P 2.3 is extinguished (or not obvious). Indicates that the charging circuit is not working.

Battery voltage measured by voltage comparator is about $13 \mathrm{~V}$, and then the low level is acquired by sampling circuit at PI 1.1 pin of MCU. It shows that the battery voltage is full and can not be charged anymore. The high level is output by PI 22.0 pin of MCU. The relay control coil of the charging control circuit loses power, the main circuit is disconnected, and the light emitting diode driven by P2.3 is extinguished (or not displayed). The charging circuit does not work ${ }^{[4]}$.

The conventional charging part is introduced into the main control circuit to match with the conventional charger, which can be charged directly with the municipal electricity. ${ }^{[5]}$.

\section{Program design}

The following is the main code completed in $\mathrm{C}$ language:

\#include "reg52.h"

\#include"intrins.h"

typedef unsigned int $\mathrm{u} 16$;

typedef unsigned char $\mathrm{u} 8$; sbit $\mathrm{LCDEN}=\mathrm{P} 2^{\wedge} 0$;

sbit $\mathrm{LCDRW}=\mathrm{P} 2^{\wedge} 1$;

sbit $\mathrm{LCDRS}=\mathrm{P} 2^{\wedge} 2$;

sbit Schnall $=\mathrm{P} 2 \wedge 3$;

sbit Schnal2 $=\mathrm{P} 2^{\wedge} 4$;

sbit Sled $1=\mathrm{P} 2^{\wedge} 5$;

sbit $\mathrm{Sled} 2=\mathrm{P} 2 \wedge 6$;

sbit Echnall $=\mathrm{P} 1 \wedge 0$;

sbit Echnal2 $=\mathrm{P} 1 \wedge 1$;

sbit $\mathrm{AD} 1 \mathrm{CS}=\mathrm{P} 1 \wedge 2$;

sbit $\mathrm{AD} 1 \mathrm{CLK}=\mathrm{P} 1 \wedge 3$;

sbit $\mathrm{AD} 1 \mathrm{IO}=\mathrm{P} 1 \wedge 4$

sbit $\mathrm{AD} 2 \mathrm{CS}=\mathrm{P} 1 \wedge 5$;

sbit $\mathrm{AD} 2 \mathrm{CLK}=\mathrm{P} 1^{\wedge} 6$;

sbit $\mathrm{AD} 2 \mathrm{IO}=\mathrm{P} 1^{\wedge} 7$;

bit flag $=0$;

u8 code LCDNUM[10] $=\{" 0123456789 "\}$;

void delay(u16 t)

\{

while(t--);

\}

u16 map(u16 mapping,u16 in_min,u16 in_max,u16

out_min,u16 out_max)

mapping,in_min,in_max,out_min,out_max)

\{

return(mapping-in $\min ) *($ out_max-

out_min)/(in_max-in_min)+out_min;

\}

void write_com(u8 com)

\{

LCDRS $=0$;

$\mathrm{LCDRW}=0$;

$\mathrm{LCDEN}=0$;

$\mathrm{P} 0=\mathrm{com}$;

$\mathrm{LCDEN}=1$;

delay(500);

$\mathrm{LCDEN}=0$;

\}

void write_date(u8 date)

\{

LCDRS $=1$;

$\mathrm{LCDRW}=0$;

$\mathrm{LCDEN}=0$;

$\mathrm{P} 0=$ date;

LCDEN $=1$;

delay(500);

$\mathrm{LCDEN}=0$;

\}

void LcdPrintStr(u $8 *$ str $)$

\{

while $\left({ }^{*} \operatorname{str} !=’ 0^{\prime}\right)$

\{

write_date $\left(*^{*} \mathrm{str}++\right)$;

delay(3000);

\}

u16 A_D1()

\{

u8 i,dat;

$\mathrm{AD} 1 \mathrm{CS}=1$;

$\mathrm{AD} 1 \mathrm{CLK}=0$;

$\mathrm{AD} 1 \mathrm{CS}=0$;

$\mathrm{AD} 1 \mathrm{IO}=1$; 


\author{
$\mathrm{AD} 1 \mathrm{CLK}=1$; \\ $\mathrm{AD} 1 \mathrm{CLK}=0$; \\ $\mathrm{AD} 1 \mathrm{IO}=1$; \\ $\mathrm{AD} 1 \mathrm{CLK}=1$; \\ $\mathrm{AD} 1 \mathrm{CLK}=0$; \\ $\mathrm{AD} 1 \mathrm{IO}=0$ \\ $\mathrm{AD} 1 \mathrm{CLK}=1$; \\ $\mathrm{AD} 1 \mathrm{CLK}=0$; \\ $\mathrm{AD} 1 \mathrm{IO}=1$; \\ for $(\mathrm{i}=0 ; \mathrm{i}<8 ; \mathrm{i}++)$ \\ \{ \\ $\mathrm{AD} 1 \mathrm{CLK}=1$; \\ $\mathrm{AD} 1 \mathrm{CLK}=0$; \\ dat $<<=1$; \\ dat=dat|AD1IO; \\ \} \\ $\mathrm{AD} 1 \mathrm{CS}=1$ \\ return dat; \\ \}
}

\section{5 summary}

In summary, the UAV wind-solar hybrid power generation system based on the AT89s51 single-chip microcomputer designed as the main control system. The system operation scheme has greatly improved the system function and leaving room for the future development of the traditional $220 \mathrm{~V}$ charging. At the same time, the design minimizes the size and reduces the weight of the drone, enhancing the flexibility of the drone and meeting the basic needs of the drone power control. This design has a good application prospect.

\section{Acknowledgement}

This project is support by: Henan Provincial Department of Science and Technology, Research Project: "Application of Wind-Solar Complementary Generation System in UAV", Project Number: 172102210113

\section{References}

1. Deere \&amp;Company; Researchers Submit Patent Application, "Unmanned Aerial Vehicle (Uav)Assisted Worksite Data Acquisition", for Approval (USPTO 20190114847)[J]. Computers, Networks \&amp; Communications,2019.

2. Sahil Vashisht,Sushma Jain. Software-defined network-enabled opportunistic offloading and charging scheme in multi-unmanned aerial vehicle ecosystem $[\mathrm{J}]$. International Journal of Communication Systems,2019,32(8).

3. Alejandro Gómez-Pazo,Augusto Pérez-Alberti,Alan Trenhaile. Recording inter-annual changes on a boulder beach in Galicia, NW Spain using an unmanned aerial vehicle[J]. Earth Surface Processes and Landforms,2019,44(5).

4. Catherine E. Waite,Geertje M. F. Heijden,Richard Field,Doreen S. Boyd. A view from above: Unmanned aerial vehicles ( UAV s) provide a new tool for assessing liana infestation in tropical forest canopies[J]. Journal of Applied Ecology,2019,56(4).

5. Muhammad Ushaq,Fang Jian Cheng,Ali Jamshaid. A Fault Tolerant SINS/GPS/CNS Integrated Navigation Scheme Realized through Federated Kalman Filter[J]. Applied Mechanics and Materials,2013,2466(332). 